\title{
Assessing the Resilience of Coastal Wetlands to Extreme Hydrologic Events Using Vegetation Indices: A Review
}

\author{
Subrina Tahsin, Stephen C. Medeiros (iD) and Arvind Singh * (iD) \\ Department of Civil, Environmental and Construction Engineering, University of Central Florida, Orlando, \\ FL 32816, USA; tahsin@knights.ucf.edu (S.T.); stephen.medeiros@ucf.edu (S.C.M.) \\ * Correspondence: arvind.singh@ucf.edu
}

Received: 7 August 2018; Accepted: 28 August 2018; Published: 31 August 2018

\begin{abstract}
Coastal wetlands (CWs) offer numerous imperative functions that support a diverse array of life forms that are poorly adapted for other environments and provide an economic base for human communities. Unfortunately, CWs have been experiencing significant threats due to meteorological and climatic fluctuations as well as anthropogenic impacts. The wetlands and marshes in Apalachicola Bay, Florida have endured the impacts of several extreme hydrologic events (EHEs) over the past few decades. These extreme hydrologic events include drought, hurricane, heavy precipitation and fluvial flooding. Remote sensing has been used and continues to demonstrate promise for acquiring spatial and temporal information about CWs thereby making it easier to track and quantify long term changes driven by EHEs. These wetland ecosystems are also adversely impacted by increased human activities such as wetland conversion to agricultural, aquaculture, industrial or residential use; construction of dikes along the shoreline; and sprawl of built areas. In this paper, we review previous works on coastal wetland resilience to EHEs. We synthesize these concepts in the context of remote sensing as the primary assessment tool with focus on derived vegetation indices to monitor CWs at regional and global scales.
\end{abstract}

Keywords: coastal wetlands; remote sensing; Normalized Difference Vegetation Index; extreme hydrologic events; resilience

\section{Introduction}

Coastal wetlands (CWs) stand as a highly productive buffer zone between the uplands and the sea and include a diverse assemblage of freshwater swamps and marshes, salt marshes, mangrove swamps, hyper-saline lagoons, mud flats, rocky shorelines, sandy beaches and sea-grass beds [1,2]. They provide numerous ecosystem services to millions of people worldwide [3]. Some valuable ecosystem services provided by CWs include shoreline protection from storm surge, key commercial and recreational fishing and water quality enhancement by nutrient uptake and filtration [4]. They also sequester carbon [5-7] and provide habitats for wetland plants and animals. In addition, CWs are among the most productive and dynamic ecosystems on earth due to the frequent interaction between land-based fluvial and coastal marine processes [8]. Their value to coastal economies and lifestyles cannot be overstated. However, CWs are very sensitive to meteorological, climatic and anthropogenic influences. Cumulative changes in temperature and precipitation, storm frequency, intensity, distribution and timing can have both direct and indirect effects on CWs and interior wetlands as well. Unfortunately, over the past 50 years, vast areas of CW have been polluted, drowned, or eroded and as a result have declined in size and health [9-12].

Extreme hydrologic events (EHEs) such as hurricanes, flooding and droughts are increasing in frequency and/or intensity as a result of climate change [13] and CWs are highly vulnerable to these 
types of hazards. Under widely accepted climate change projections, CWs are expected to experience increased depth and duration of inundation due to sea level rise (SLR), changes in distribution and intensity of fluvial freshwater inputs that are influenced by changes in precipitation patterns and increased temperature $[14,15]$.

Accurately capturing the spatio-temporal dynamics of CWs requires vast amounts of information. In this context, vast indicates quantity in both space and time. Remote sensing (RS) has enabled major advances in understanding CWs and their changes by quantifying internal processes and their interaction with spatio-temporal states of the atmosphere, land and ocean. For monitoring CWs, RS has many advantages including recurrent coverage for CWs to be monitored seasonally or yearly. It is especially appropriate for CW inventories and monitoring in developing countries, where funds are limited and where little information is available on the areas, surrounding land uses and wetland losses over time [16]. In these ungagged areas, ground truth data is limited therefore techniques developed and refined elsewhere must be applied. Vegetation and water indices are prominent examples of generalizable and widely applicable classes of RS abstraction. Modern improvements in sensor design and advanced data analysis techniques are making RS systems practical and attractive for monitoring natural and man-induced coastal ecosystem changes. Nevertheless, the relatively short durations of observation series and their uncertainties still pose challenges for capturing the robust long-term trends within the landscape and ecosystem [11].

Here we present a literature review of contemporary RS platforms and their associated index products to investigate CW dynamics. This technology has been used in both coastal and inland wetland research areas such as land use/cover changes, wetland classification [4-8] and hydrologic processes in wetlands [17-19]. However, the existing work is curated to synthesize the most relevant and current trends in RS technology for CW change detection, particularly in response to EHE impacts utilizing RS derived vegetation indices. Therefore, the objectives of this paper are to: (i) present an overview of the threats from EHEs on CWs; (ii) highlight different types of RS tools to monitor CW changes using RS-derived indices due to hurricanes, droughts and floods; (iii) present contemporary RS approaches (using lower level sensor data rather than abstracted indices) to monitor EHE impacts on CWs and (iv) provide suggestions for future research in this area.

\section{Threat Profile for Extreme Hydrologic Events on Coastal Wetlands}

Coastal wetlands collectively include marshes, mangroves, forested wetlands and estuaries. Survival of CWs depends largely on their ability to adapt and recover from EHEs and in addition to acute and long-term anthropogenic impacts. Once again, the EHEs referenced here include coastal flood/storm surge, hurricane and drought that cause geophysical changes to the landscape.

The particular changes driven by EHEs include geomorphology (sediment deposition and erosion), geochemical (concentration or dilution of salinity) and biologic (damage and destruction of vegetation, transport and deposition of invasive species). Wilcox [17] found that local scale geomorphic changes such as sedimentation altered wetland hydro-period and internal creek depth. Day et al. [18] provided a hierarchy of hydrologic pulse events ranging from daily tides, weekly sediment deposition to long term river channel major changes that affected the sustainability of various CWs. Meteorological changes in wetlands such as area change, topographical alteration along with SLR, storms, sedimentation and changing freshwater input can directly impact coastal and estuarine wetlands. The synergistic biological processes can also influence these physical impacts and geomorphological changes to CWs resulting in unanticipated outcomes for the ecosystem [18].

A 2002 review of the marine resource literature summarized the potential impacts of natural events on CWs, shorelines and estuaries [15]. The assessment considered several key visible effects of climate change such as SLR, alterations in precipitation patterns and subsequent delivery of freshwater, increased ocean temperature and changes in frequency and intensity of coastal storms. Global sea levels are documented to have continuously risen through the 20th century and this is projected to accelerate through the 21st century due to global warming. The increase in water temperature along 
with changes in freshwater delivery and coastal hydro-periods have the potential to alter the trophic state of CW [19]. Although these impending impacts from climate change will vary in magnitude across CW types, the synergistic intensification of these impacts could trigger other ecosystem stresses such as coastal pollution, habitat destruction and irrecoverable physical damage [15].

Tahsin et al. [20] conducted a study in 2016 of the CW system in Apalachicola Bay, FL, USA. This area has experienced several tropical cyclones and droughts in 2005, 2009 and 2012-2013. Another study was conducted to evaluate the impact of hurricane Andrew on CWs in Louisiana [21]. Both of these studies suggest that marshes and forested wetlands that are less salt tolerant are particularly vulnerable to storm surge impacts. During Hurricane Andrew in Louisiana, large amounts of sediment moved into marshes and low salinity areas and suppressed vegetation. Salinity introduced into fresh water ecosystem zones from the storm surge resulted in salt burn [21]. Similar vegetation suppression was observed in Apalachicola Bay during the hurricane season of 2004-2005 [20]. Although freshwater wetland plants re-establish in three months to a year, more frequent and larger magnitude storms are likely to dampen recovery of these freshwater wetlands and threaten their long-term resilience [21-23].

Table 1 summarizes potential threats posed by EHEs and also documents recommended methods to mitigate the threats. Note that anthropogenic disturbances are not considered in this study and will be a subject of future research. In Table 1, EHEs were arranged according to the change occurring in landscape.

Table 1. Summary of Threats in Coastal Wetlands and Recommended Actions for Recovery.

\begin{tabular}{|c|c|c|}
\hline Threat Types & Brief Description & Recommended Methods \\
\hline \multicolumn{3}{|c|}{ Extreme events-Meteorological Changes } \\
\hline Wetland acreage decrease & $\begin{array}{l}\text { Sea Level Rise (SLR, aggregated with } \\
\text { human activities) }\end{array}$ & $\begin{array}{l}\text { Wetland protection, restoration (removing } \\
\text { exotic plants, removing bulkheads and fill, } \\
\text { elevation grading, creating flushing } \\
\text { channels and planting native vegetation) } \\
\text { and improvement of stressed systems [24] }\end{array}$ \\
\hline Wetland shrinkage & $\begin{array}{l}\text { SLR converts Coastal Wetlands (CWs) } \\
\text { into open water }\end{array}$ & $\begin{array}{l}\text { Artificial wetland creation, conservation } \\
\text { of potential migration areas [25] }\end{array}$ \\
\hline $\begin{array}{l}\text { Surface elevation of CW } \\
\text { cannot keep pace with SLR }\end{array}$ & $\begin{array}{l}\text { SLR threatens coastal salt-marshes and } \\
\text { mangrove forests }\end{array}$ & $\begin{array}{l}\text { Coastal climate change adaptation policy } \\
\text { and expansion of monitoring [3] }\end{array}$ \\
\hline $\begin{array}{l}\text { Topographically alteration } \\
\text { in the Watershed }\end{array}$ & $\begin{array}{l}\text { Alterations can damage the natural } \\
\text { hydrology of watershed area, including } \\
\text { concentration pits, terraces, diversions, } \\
\text { stream channelization, ditches and others. }\end{array}$ & $\begin{array}{l}\text { New Wetland Creation; Channel } \\
\text { Excavation or Backfill [25] }\end{array}$ \\
\hline \multicolumn{3}{|c|}{ Geomorphological Changes } \\
\hline $\begin{array}{l}\text { Alteration of CW's } \\
\text { geomorphology }\end{array}$ & $\begin{array}{l}\text { Intense and frequent hurricanes, SLR, } \\
\text { changes in sediment, nutrient inputs and } \\
\text { freshwater }\end{array}$ & $\begin{array}{l}\text { Changes in human behavior for } \\
\text { dependency on wetland [4] }\end{array}$ \\
\hline Sediment accumulation & $\begin{array}{l}\text { Culturally-accelerated sedimentation } \\
\text { alters the natural depths and } \\
\text { hydro-periods of wetlands }\end{array}$ & Filled Wetland Construction [17] \\
\hline \multicolumn{3}{|c|}{ Biological Changes } \\
\hline Invasive species & $\begin{array}{l}\text { Intrusion of invasive species can reduce } \\
\text { habitat diversity }\end{array}$ & Biological Removal; Prescribed burn [17] \\
\hline
\end{tabular}

\section{Remote Sensing Vegetation Indices Used to Monitor Extreme Hydrologic Event Impacts}

Scientists and engineers have developed indices for quantitatively and qualitatively evaluating vegetation cover, vigor and growth dynamics using spectral measurements. Vegetation indices (VI) have been derived using multiple airborne and satellite platforms, including a recent increase in the use of data acquired by Unmanned Aerial Systems (UAS). To the best of authors' knowledge, there is no integrated mathematical expression to unify all VIs because of the use of different light spectra combinations, platforms and resolutions. Therefore, customized algorithms tried over a variety of 
applications expressed in specific mathematical frameworks have been developed. To obtain proxy quantifications of the vegetation surface, the frameworks often use visible light reflectance, mainly red and green spectral regions, from vegetation and combine it with nonvisible spectra such as near infrared [26]. However, while each VI is developed using specific techniques, the end user (ecologist, coastal engineer, geographer) bases their decision on the attributes of their particular use case such as target, spatial and temporal resolution requirements and desired deliverables (Table 2). Therefore, RS scientists and engineers would be well served by involving end users in research projects from the start in order to identify and meet their needs.

More than 100 VIs are currently in use [26]. Again, with the use of high resolution spectral instrumentation in RS, the number of available channels is increasing, while their bandwidth is getting narrower [27]. One index calculated from multispectral information is the normalized ratio between the red (R) and near infrared (NIR) bands, known as the Normalized Difference Vegetation Index (NDVI) [28], that characterizes canopy growth or vigor. Among the earliest basic VIs, Ratio Vegetation Index (RVI), Difference Vegetation Index (DVI) and NDVI depend on R and NIR bands, while Perpendicular Vegetation Index (PVI) depends on soil reflectance and vegetation reflectivity. These VIs have limitations, mainly attributed to sensitivities to sparse vegetation (RVI, PVI); soil background (DVI, NDVI, PVI) [29]; and atmospheric effects (NDVI). Later, new VIs were developed to address different issues. For example, Atmospherically Resistant Vegetation Index (ARVI) has been developed to account for atmospheric effects and Transformed Soil-Adjusted Vegetation Index (TSAVI), Soil-Adjusted Vegetation Index (SAVI) and modified SAVI (MSAVI) were established to account for the effect of soil background. Different environments have their own complex characteristics so for practical applications; the suitability of a particular VI must be scrutinized for the target scenario. To assist in that determination, we present a review of recent studies on VIs used to monitor EHE driven impacts such as hurricane, drought and flood in CWs (Table 2). There is also a category of studies that used RS spectral information or primary data directly to identify EHE impacts, which will be discussed in the following section.

\subsection{Vegetation Indices to Assess Hurricane Impacts in Coastal Wetlands}

\subsubsection{Normalized Difference Vegetation Index Derived Studies}

Extreme hydrologic events play a central role in the dynamics of CWs. NDVI is one of the most widely used VIs to monitor plant growth and vegetation cover and thus it is a good candidate to assess long term CW changes. Both medium (LANDSAT [30]) and coarse resolution (Advanced Very High Resolution Radiometer (AVHRR)) [31], Moderate Resolution Imaging Spectroradiometer (MODIS) [32]) satellite remote sensors have been used successfully in the past providing CW changes or recovery from hurricanes. For example, medium resolution Landsat 5 NDVI data were obtained to investigate coastal vegetation changes before and after Hurricane Katrina in 2005 for the Weeks Bay Natural Estuarine Research Reserve and surrounding areas of coastal Alabama. Three NDVI images for selected dates before landfall (24 March 2005), after landfall (16 September 2005) and 8 months after landfall (28 April 2006) showed that the NDVI values of coastal emergent wetland continued to decrease by $27 \%$ from September 2005 to April 2006 indicating prolonged hurricane damage in the study area [30]. NDVI is often used to determine the effects of hurricanes on CW, including mangrove ecosystems that can vary from minor defoliation of a few trees to disastrous blow-down of an entire stand. An NDVI time series from 2001 to 2010 with an 8-day interval derived from the coarse resolution satellite image MODIS Terra to detect the recovery rate of mangrove after the two major hurricanes in South Florida. They found that it took around 2 to 3 years for mangrove ecosystem to recover to their phonological tempos [33].

In August 1992, Hurricane Andrew made landfall in Louisiana and provided researchers the opportunity to use the coarse resolution AVHRR imagery to assess the impacted area of forested wetlands in Louisiana [31]. To better understand the phenology, a time series of AVHRR images 
were transformed into NDVI. The comparative analysis among three study sites (Site 1: a fairly open canopy; Site 2, a hardwood area; and Site 3, a hardwood area with the highest canopy closure) in the Atchafalaya Basin validated the anomalous phenology pattern of all sites in 1992 resulting from the hurricane. The differences in damage across three sites were correlated with the forest canopy structure. A recent study using VIs at multiple spatial resolutions, closely monitored the vulnerability of coastal marshes in Louisiana [34]. They found that linear models derived from NDVI and Enhanced vegetation index (EVI) are most effective for assessing Leaf Area Index (LAI). They studied various optical remote sensors including Landsat MSS, TM, ETM+ and OLI; ASTER; AVHRR; MODIS; SPOT and SENTINEL-2 multispectral instrument (MSI) derived VIs such as Simple Ratio (SR), NDVI, ARVI, SAVI, Soil and Atmosphere Resistant Vegetation Index (SARVI) and EVI. The study also highlighted the effect of spatial resolution on biomass mapping of $\mathrm{CW}$ and found that sensors with high spatial resolution are preferred for mapping biomass in areas with dense water networks and areas along shorelines.

A Case-Study of Coastal Wetland Dynamics: 30-Year Landsat NDVI Time-Series Analysis to Monitor Extreme Hydrologic Event Impacts

The health and vigor of the vegetation in the lower marshes of Apalachicola Bay have been detectably altered as a result of hurricanes and droughts. These changes were illustrated in an analysis of 15 years of NDVI data for this region. Tahsin et al. [20] derived NDVI derived using Landsat 5, 7 and 8 sensors from 2000 to 2015 and investigated the external stresses incurred by hurricanes and droughts on Saltwater Wetland (SW), Freshwater Forested Wetland (FFW) and Freshwater Emergent Wetland (FEW) ecosystems using both annual averaged and monthly NDVI from 1984 to 2000. The CW ecosystem boundary was consolidated from the 23 wetland classifications of the National Oceanic and Atmospheric Administration (NOAA) Coastal Change Analysis Program (C-CAP) down to 3 the classes of wetlands mentioned above. Probability density functions and NDVI difference computations against each year showed that SW was more resilient than the other two ecosystems [20].

Using the same data set, we generated Figure 1 to demonstrate the spatial NDVI variability averaged annually, from 2001 to 2015. Low NDVI values represent wetland with less greenness; high NDVI values represent wetland with more greenness. While 2002 was a regular non-event year, 2004 and 2005 had significant storm surges from Hurricanes Frances, Ivan and Dennis. 2012 was classified as a drought year [35]. The mean annual NDVI values in the study area were found to be $0.52,0.49$, 0.34 and 0.41 in 2002, 2004, 2005 and 2012, respectively. The aftermath of each hurricane mentioned above was observed for a year from the month it made landfall. 2004 and especially 2005 showed the least greenness or most stress for CW in Apalachicola Bay due to repeated hurricane strikes. Drought also impacted the average NDVI range in 2012-2013.

In this paper, we extended the Apalachicola Bay NDVI time-series back by an additional fifteen years from 1984 to 1999; bring the temporal extent of the data to 30 years. The data are similar except that the ecosystems were previously reclassified into three classes, based on the relatively minor differences between the two freshwater classes; they were now reclassified into two: saltwater wetland (SW) and freshwater wetlands (FW). Freshwater wetlands are the dominant type in the study area and are characterized by woody vegetation that is $6 \mathrm{~m}$ tall or taller. All hydro period regimes were included except sub tidal. This rough categorization is important since each wetland type has different "typical" NDVI ranges. To illustrate this, the monthly average NDVI were computed for both wetland types from 1984 to 2015 and the results are shown in Figure 2. Also note that the data ranging from 2000-2015 has all months of data from January to December while data ranging from 1984-2000 has several months of missing data in each year. The data gaps caused by cloudy/missing data may have resulted in a narrower range of box plots for some years from 1984 to 2000. For example, 1992 has only 6 months of data for both FW and SW.

Figure 2 shows the extension of the previous work to include 30 years of CW dynamics at Apalachicola Bay in the midst of repeated EHEs. 25th percentile NDVI values were calculated for both FW and SW which are 0.33 and 0.24 , respectively. The time series in Figure 2 indicates that NDVI 
of both FW and SW were below the 25th percentile range during 1985, 1994, 1995, 1996, 2005, 2007, 2009, 2011-2012, 2013 suggesting wetland stresses in those years. Apalachicola Bay was impacted by Hurricane Elena, Hurricane Dennis, Hurricane Claudette in 1985, 2005 and 2013, respectively. Tropical storms followed by flood impacted Apalachicola Bay during 1994-1996 and droughts were intermittently observed from 2011-2013 [36]. Note that Tahsin et al. [20] reported similar findings regarding NDVI dynamics showing drops at 2005, 2009 and 2011-2012.

2001

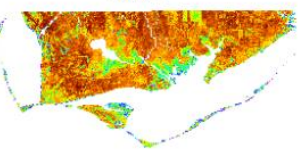

2005

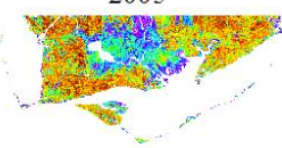

2009

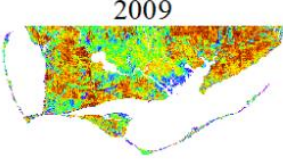

2013

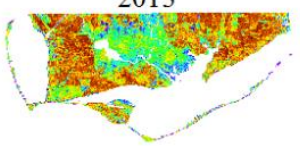

2002

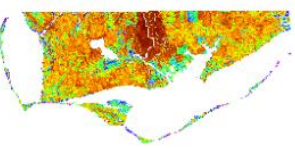

2006

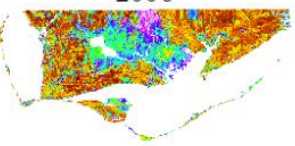

2010

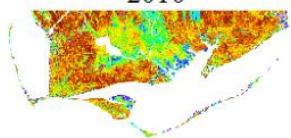

2014

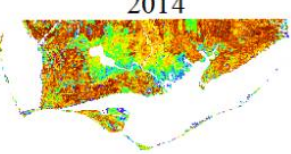

2003

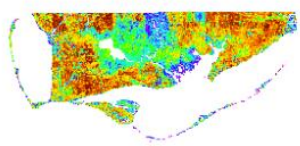

2007

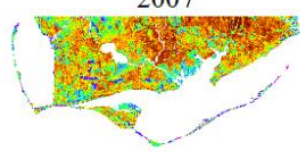

2011

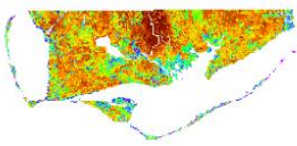

2015

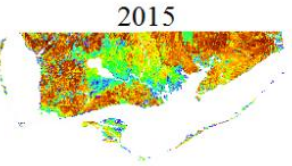

2004

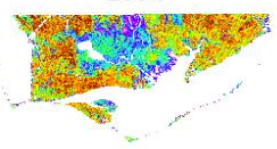

2008

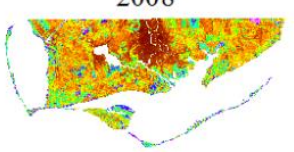

2012

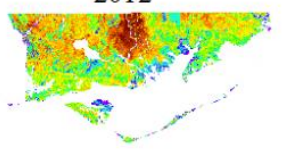

Legend

NDVI
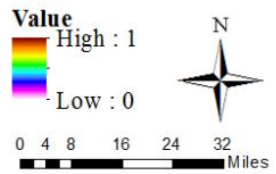

Figure 1. Temporal pattern of annual averaged Normalized Difference Vegetation Index (NDVI) from 2001 to 2015. Low NDVIs were observed during 2003-2005 (known hurricane years), 2009 (known hurricane year) and 2012-2013 (known drought and tropical storm years).
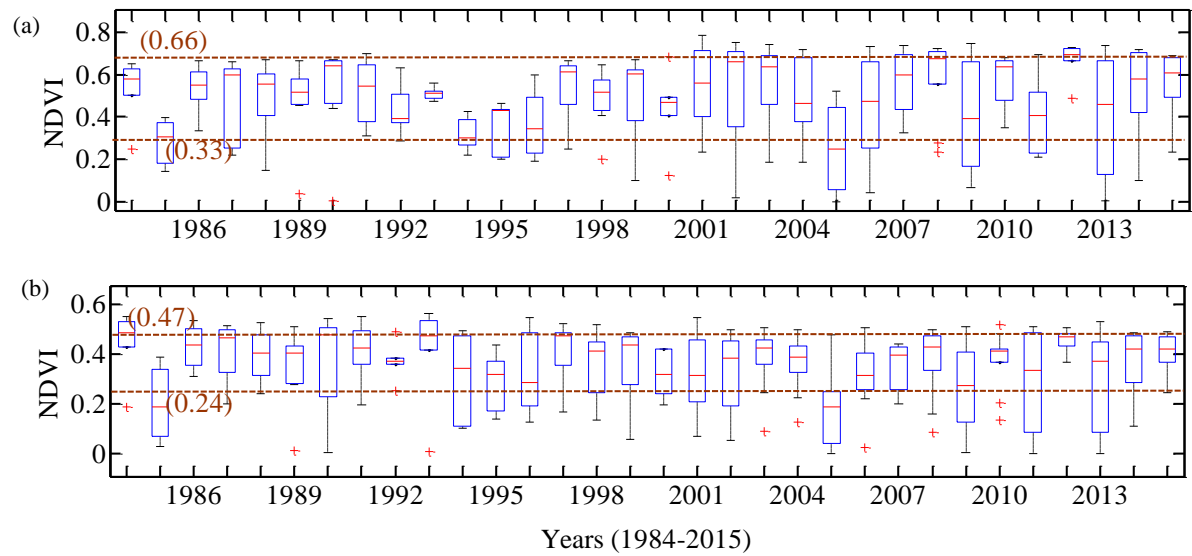

Figure 2. Boxplots of 30 Years of Vegetation Dynamics (Normalized Difference Vegetation Index, NDVI) at Apalachicola Bay for the (a) Freshwater Wetland (FW) and (b) Saltwater Wetland (SW). Horizontal line (red line) in $(\mathbf{a}, \mathbf{b})$, in each box indicates median demarcating 50\% data either above or below the median whereas the dashed (brown) horizontal lines represent the average 25th and 75th percentiles for the two types of the wetlands studied here (corresponding percentile values are written inside parenthesis adjacent to the dashed brown lines). 


\subsubsection{Ehhanced Vegetation Index Studies}

EVI is a vegetation index that enhances the vegetation signal in areas with high biomass. Using MODIS NIR, R and Blue (B) surface reflectance, EVI can be expressed as:

$$
\mathrm{EVI}=\frac{\mathrm{G} \times(\mathrm{NIR}-\mathrm{R})}{(\mathrm{NIR}+\mathrm{a} \times \mathrm{R}-\mathrm{b} \times \mathrm{B}+\mathrm{L})}
$$

The coefficients adopted in the MODIS-EVI algorithm are: L (Canopy background adjustment factor) $=1, a=6, b=7.5$ and $G$ (gain factor) $=2.5$ [37]. A time series of MODIS EVI (from 2000 to 2017) was produced over Puerto Rico to determine the severity of the disturbance caused by Hurricane Maria compared to other events over the same period [38]. Analysis of the MODIS EVI vegetation index demonstrated a steep decline in vegetation greenness outside of the historical range since 2000 when compared with 13 September (post Hurricane Irma), with a much steeper decline in at 29 September (post Hurricane Maria). Wang and D'Sa [39], revealed the usefulness of the MODIS EVI product for long-term CW monitoring after a hurricane disturbance in Mexico. Also, the EVI product can detect both disturbed and non-disturbed CW by the hurricanes. Using MODIS EVI product again, another study mapped Hurricane Dean (August 2007) damage to the forests in the Yucatán Peninsula of Mexico using a two-step vetting procedure. Capitalizing on the favorable timing of the MODIS Aqua EVI compositing, relative to the hurricane event, they revealed highest damage detection ranging from 95\% (Saffir-Simpson hurricane wind scale zone 5) to $87 \%$ (zone 3) [40]. A comparative study between MODIS and Landsat TM VIs illustrated that Landsat TM-derived NDVI imagery was more sensitive to terrain properties than EVI. However, both indices either under or over-estimated VI values in areas of steep topography, especially when the sun elevation angle was less than $40^{\circ}$ (TM images). An additional limitation of TM imagery is that fewer cloud-free images are typically available compared to MODIS composite images. Also, MODIS NDVI outperforms MODIS EVI in areas of steep topography particularly during seasons with poor viewing geometry [41,42].

\subsubsection{Soil Adjusted Vegetation Index Studies}

Soil Adjusted Vegetation Index (SAVI) was developed as a modification of NDVI to account for the influence of soil brightness when vegetative cover is low [43]. In response to the need for effective restoration of threatened estuarine wetlands in the Gulf Coast, a study for mapping biophysical health of the area was initiated. The study used multiple VIs consisting NDVI, EVI, SAVI, Chlorophyll Index (CIred), Wide Dynamic Range Vegetation Index (WDRVI) and Visible Atmospheric Resistant Index (VARI) utilizing reflectance at Red and NIR bands for MODIS. Another study aimed to generate a RS model of coastal marsh aboveground biomass density to represent nationally diverse tidal marshes within the conterminous United States [44]. Using the random forest machine learning algorithm, imagery from multiple sensors including Sentinel-1 C-band synthetic aperture radar, Landsat and the National Agriculture Imagery Program (NAIP), the model performance was improved. SAVI was identified as the most important VI among the six Landsat VIs that successfully predicted biomass density for a range of marsh plants.

\subsubsection{Other Vegetation Index Studies}

Among other VIs, a recent study by Khanna et al. [45] used a modified NDVI (mNDVI) to evaluate the recovery of the salt marshes in Barataria Bay, LA, USA, after Hurricane Isaac in 2012 and the DeepWater Horizon oil spill in 2010 [45]. In 2012, after Hurricane Isaac, there was a significant loss of green vegetation to water, soil and non-photosynthetic vegetation (NPV) in both oiled and oil-free sites. Also, vegetation in narrow stands of the Bay was considerably more stressed than vegetation in block stands. Another study developed an approach for identifying and estimating forest damage from Hurricane Katrina [46]. The statistical analysis and comparison with the damage severity revealed that Normalized Difference Infrared Index (NDII) was an optimal indicator for detecting hurricane-induced 
forest damage among the five commonly used VIs, including NDVI, EVI, NDII, LAI and Fraction of Photosynthetically Active Radiation (FPAR).

\subsection{Remote Sensing Systems and Indices to Monitor Drought Impacts}

According to the American Meteorological Society, a meteorological drought is defined by the magnitude (with respect to normal) and duration (e.g., weekly, monthly, seasonal, or annual time scales) of a precipitation deficit [47]. Many in-situ meteorological based drought indices such as the Palmer Drought Severity Index (PDSI), Standard Precipitation Index (SPI), along with precipitation percent normal and deciles have been developed for monitoring drought conditions due to their importance in assessing agricultural and wildfire risks [48,49]. Satellite image-based drought indices such as the NDVI or Vegetation Index based on Universal Pattern Decomposition (VIUPD)based Vegetation Condition Index (VCI), have proven to be useful for detecting drought onset and measuring the intensity, duration and impact of drought in regions around the world [50-53]. Mo et al. [54] used Landsat-derived NDVI and field-based environmental data during the past 30 years to study the drought-associated phenological changes of Louisiana coastal marshes. They found correlation between drought in southeast Louisiana and La Niña. They also pointed out the sensitivity of saline marshes to drought. Another study applied change analysis method using high-resolution IKONOS and WorldView-2 satellite imagery to identify the annual rates of change from mudflat to vegetation in a coastal wetland (Tidal march) restoration area. Not only the effects of wet years and drought, the trends of the vegetation in that tidal marsh area were likely influenced by a combination of other factors such as sedimentation rates [55].

A number of studies used satellite image-derived VIs for drought monitoring other than CWs that paved the path to use the VIs for drought monitoring in CWs as well. For example, the combination of MODIS derived NDVI as well as Land Surface Temperature (LST) provided very useful information for agricultural drought monitoring and early warning system for farmers [56]. Zhang et al. [57] examined the impacts of the 2009/2010 drought in southwestern China on vegetation by calculating the standardized anomalies of NDVI, EVI, Normalized Difference Water Index (NDWI) LST. The indices were derived by MODIS satellite images. The results implied that the NDVI, EVI and NDWI declined, while LST increased in the 2009/2010 drought-stricken vegetated areas during the drought period. Zi and Peters [50] established that, while NDVI is a useful variable for monitoring vegetation conditions, the nature of the relationship between the NDVI and drought conditions varies based on the seasonal timing and variations in vegetation and soil type [50].

\subsection{Remote Sensing Systems and Indices to Monitor Flood Impacts}

Flood impacts resulting from heavy rainfall, storm surge and drainage system failures are regularly experienced in coastal and inland areas. Remote sensing has played an important role in characterizing these hazards and assessing their effects. Waite and MacDonald first spotlighted flooded forests during "leaf off" conditions in Arkansas where they showed up as anomalously bright areas on K-band Radio Detection and Ranging (Radar) images [58]. During that time, many studies relied on the fact that when standing water is present beneath the vegetation canopies, the radar backscattering signal changes with water level, depending on vegetation type and structure. Therefore, they used synthetic aperture radar (SAR) backscatter to monitor temporal variations in the hydrological conditions of wetlands, including floods [59-64]. Previous studies using satellite SAR imagery over coastal Louisiana were focused on flood detection in wetlands with a limited number of scenes $[64,65]$. A study on the Louisiana coast investigated the feasibility of using Radarsat-1 SAR imagery to detect flooded areas in coastal Louisiana after Hurricane Lili, October 2002. Arithmetic differencing and multi-temporal enhancement techniques were employed to detect flooding and investigate relationships between backscatter and water level changes [64]. 
Table 2. List of remote sensing (RS) systems derived vegetation indices (VIs) used in past studies on coastal wetland (CW) resiliency under extreme hydrologic events (EHEs) driven impacts.

\begin{tabular}{|c|c|c|c|c|c|}
\hline Index & RS System/Images & Spatial Resolution (m) & Research Topics & Image Used & References \\
\hline \multicolumn{6}{|c|}{ EHE-Hurricane } \\
\hline $\mathrm{q}$ & Landsat-5 & $30 \mathrm{~m}$ & $\begin{array}{l}\text { Impacts of Hurricane Katrina at } 2005 \text { at coastal vegetation at Weeks } \\
\text { Bay Reserve and surrounding area of coastal AL }\end{array}$ & $\begin{array}{l}3 \text { Images before landfall, after landfall, } 8 \text { months after } \\
\text { landfall }\end{array}$ & [30] \\
\hline NDVI & MODIS-Terra & $1 \mathrm{~km}$ & $\begin{array}{l}\text { Recovery rate of mangrove after the two major hurricanes in South } \\
\text { Florida }\end{array}$ & 10 years (2001 to 2010) time series & [33] \\
\hline NDVI & AVHRR & $1.1 \mathrm{~km}$ & To assess the impacted area of forested wetlands at Louisiana & $\begin{array}{l}2 \text { years (1991-1993) time series between June and } \\
\text { November, plus a Composite image during } 1993 \text { June }\end{array}$ & [31] \\
\hline $\begin{array}{l}\text { SR, NDVI, ARVI, SAVI, } \\
\text { SARVI, EVI }\end{array}$ & $\begin{array}{l}\text { Landsat-MSS, TM, ETM+, OLI; ASTER; } \\
\text { AVHRR; MODIS; SPOT; SENTINEL-2 MSI }\end{array}$ & $\begin{array}{r}\text { Multiple }(30 \mathrm{~m} 15 \mathrm{~m}, \\
1.1 \mathrm{~km} 1 \mathrm{~km} 10 \mathrm{~m} 20 \mathrm{~m})\end{array}$ & Biomass mapping of a marsh $\mathrm{CW}$ & & [34] \\
\hline NDVI & Landsat 5 and 7 & $30 \mathrm{~m}$ & CW resilience under EHEs from 1984 to 2015 at Apalachicola Bay & 30-year time-series & [20] \\
\hline EVI & MODIS-Terra and Aqua & $250 \mathrm{~m}$ & $\begin{array}{l}\text { Hurricane Dean (August 2007) damage map to the forests in the } \\
\text { Yucatán Peninsula of Mexico }\end{array}$ & $\begin{array}{l}\text { Pre-hurricane EVI composites (2007): } 20 \text { July (Aqua), } 28 \\
\text { July (Terra), } 5 \text { August (Aqua), } 13 \text { August (Terra). } \\
\text { Post-hurricane composites: } 21 \text { August (Aqua), } 29 \text { August } \\
\text { (Terra), } 6 \text { September (Aqua), } 14 \text { September (Terra) } 22 \\
\text { September (Aqua). }\end{array}$ & [40] \\
\hline mNDVI & AVIRIS & $20 \mathrm{~m}$ & $\begin{array}{l}\text { To investigate the ability of the saltmarshes in Barataria Bay, } \\
\text { Louisiana, USA, to recover hurricane Isaac in } 2012\end{array}$ & $\begin{array}{l}3 \text { images -14 September } 2010 \text { (DeepWater Horizon oil spill) } \\
15 \text { August } 201119 \text { October } 2012 \text { (Hurricane Isaac) }\end{array}$ & [45] \\
\hline NDII & MODIS & $1 \mathrm{~km}$ & $\begin{array}{l}\text { Identify and estimate forest damage impacted by Hurricane } \\
\text { Katrina }\end{array}$ & $\begin{array}{l}3 \text { years (2003-2006) time series of vegetation indices Total } \\
24 \text { images were available }\end{array}$ & [46] \\
\hline \multicolumn{6}{|c|}{ EHE-Drought } \\
\hline VCI & AVHRR & $1.1 \mathrm{~km}$ & $\begin{array}{l}\text { Detect drought onset and measure the intensity, duration and } \\
\text { impact of drought }\end{array}$ & 5-year (1985-1990) time-series & [52] \\
\hline $\begin{array}{l}\text { VCI, PDSI, SPI, percent } \\
\text { normal, deciles }\end{array}$ & AVHRR & $8 \mathrm{~km}$ & Monitoring drought at Texas & Images of 18 growing-seasons (March to August 1982-1999) & [49] \\
\hline NDVI & MODIS & $250 \mathrm{~m}$ & $\begin{array}{l}\text { agricultural drought monitoring and early warning system for the } \\
\text { farmers }\end{array}$ & 10 years (2002-2012) monthly & [56] \\
\hline NDVI, EVI, NDWI, LST. & MODIS & $1 \mathrm{~km}$ and $0.5 \mathrm{~km}$ & $\begin{array}{l}\text { impacts of the 2009/2010 drought in southwestern China on } \\
\text { vegetation }\end{array}$ & 4 sets of 11 years (2000-2011) time-series & [57] \\
\hline VIUPD derived VCI & MODIS & $250 \mathrm{~m}$ & longer-term drought monitoring, such as agricultural droughts & 2011 (April-October) & [53] \\
\hline \multicolumn{6}{|c|}{ EHE-Flood } \\
\hline $\mathrm{N} / \mathrm{A}$ & K-band radar images & N/A & standing water is present beneath the vegetation canopies & & [58] \\
\hline $\mathrm{N} / \mathrm{A}$ & SAR & $\mathrm{N} / \mathrm{A}$ & Flood detection in wetland with a limited number of scenes & limited scenes after 29 August 2005 & {$[64,65]$} \\
\hline $\mathrm{N} / \mathrm{A}$ & IRS LISS III, 1999 and Landsat TM, 1995 & Multiple $(2.5 \mathrm{~m} ; 30 \mathrm{~m})$ & mapping the flood-affected areas in Koa catchment, Bihar & $\begin{array}{l}\text { Landsat TM: } 27 \text { May 1995-18 October } 1995 \text { IRS-1C LISS III: } \\
\text { March 1999; December } 1999\end{array}$ & [66] \\
\hline NDWI & Landsat TM, ETM+ & $30 \mathrm{~m}$ & to identify flood inundated in New South Wales & $\begin{array}{l}21 \text { years (1989-2010) time-series data: Landsat } 5 \text { TM and } \\
\text { Landsat } 7 \text { ETM+ images }\end{array}$ & [67] \\
\hline mNDWI & LANDSAT & $30 \mathrm{~m}$ & spectral analysis for flooded area prediction & & [68] \\
\hline
\end{tabular}


Jain et al. [66] mapped the flood-affected areas in Koa catchment, Bihar in India using RS satellite data (IRS LISS III, 1999 and Landsat TM, 1995). They derived water indices using image processing techniques and indicated that a NDWI based approach was able to identify flood inundation. NDWI derived from Landsat TM and ETM+ images were also used to map the inundation in New South Wales, NSW, Australia [67]. Another study generated a flood inundation map using a geomorphologic approach employing Shuttle Radar Topographic Mission (SRTM) DEM and satellite image data (ASTER and Landsat). They integrated both landform classification and spectral analysis for flooded area prediction by applying modified NDWI (MNDWI) and elevation range to assess flood inundation condition of an alluvial plain in central Vietnam [68]. The study suggested that the extraction of moist soil by MNDWI can help to detect flooded sites; results were also compared with the landform classification map, SRTM DEM elevation ranges and land cover classification [68].

\section{Satellite/Airborne Imagery and Remote Sensors Primary Data for Assessing the Impacts of Extreme Hydrologic Events}

In addition to abstracted indices, the primary data generated by aerial and remote sensors have been used to develop flood maps. Different techniques for flood mapping using active and passive RS systems have been developed and applied in several studies. Flood mapping of hurricane storm surge or inland flooding by passive RS systems includes identifying the water versus non-water areas and determining flooded area during the flood event. Table 3 lists the satellites used in past studies to identify EHE impacts on CWs based on spectral reflectance or primary data obtained from corresponding RS system. The order of satellites in Table 3 is presented based on spatial resolution (high/medium/low). Active sensors such as RADARSAT-1 are usually classified as medium resolution and therefore are placed in that resolution category [69]. The advantages and disadvantages of each sensor are discussed briefly at the end of each category.

Table 3. Remote sensors used in past studies on CW resilience under EHEs.

\begin{tabular}{|c|c|c|c|c|c|}
\hline Satellite & Sensor & $\begin{array}{c}\text { Date/ } \\
\text { Decommission }\end{array}$ & $\begin{array}{c}\text { Spatial } \\
\text { Resolution (m) }\end{array}$ & Spectral Resolution & Repeat Cycle (days) \\
\hline \multicolumn{6}{|c|}{ High Resolution Sensor } \\
\hline $\begin{array}{c}\text { WorldView-1 \& } 2 \\
{[70]}\end{array}$ & ${ }^{*} \mathrm{PAN},{ }^{*} \mathrm{MS}$ & $\begin{array}{l}18 \text { September } \\
2007 ; 8 \text { October } \\
2009\end{array}$ & $0.46 \mathrm{~m}$ (both 1 and 2 ) & $\begin{array}{c}\text { PAN }(0.40-0.90 \mu \mathrm{m}) ; \mathrm{MS} \\
(0.40-1.04 \mu \mathrm{m})\end{array}$ & $\begin{array}{c}1.7 \text { days }(\leq 1 \mathrm{~m} \mathrm{GSD}) \\
5.9 \text { days }(0.51 \mathrm{~m} * \\
\text { GSD); } 1.1 \text { days }(\leq 1 \mathrm{~m} \\
\text { GSD) } 3.7 \text { days }(0.52 \mathrm{~m} \\
\text { GSD) }\end{array}$ \\
\hline QuickBird [71], & BGIS 2000 sensor & 18 October 2001 & $\begin{array}{l}\text { PAN: } 0.65 \mathrm{~m} \text { (nadir) } \\
\text { to } 0.73 \mathrm{~m}\left(20^{\circ}\right. \\
\text { off-nadir) MS: } 2.62 \mathrm{~m} \\
\text { (nadir) to } 2.90 \mathrm{~m}(20 \\
\text { off-nadir) }\end{array}$ & $\begin{array}{l}\text { PAN }(0.45-0.90 \mu \mathrm{m}) ; \text { MS } \\
(0.45-0.52 \mu \mathrm{m} ; 0.52-0.60 \mu \mathrm{m} ; \\
0.63-0.69 \mu \mathrm{m} ; 0.76-0.90 \mu \mathrm{m})\end{array}$ & $\begin{array}{l}\text { 1-3.5 days, depending } \\
\text { on latitude ( } 30^{\circ} \\
\text { off-nadir) }\end{array}$ \\
\hline IKONOS [72] & $\begin{array}{l}\text { laser sensors, imagers, } \\
\text { radar sensors, } \\
\text { electro-optical } \\
\text { astronomical sensors, } \\
\text { planetary sensors }\end{array}$ & $\begin{array}{l}24 \text { September } \\
1999\end{array}$ & $\begin{array}{l}\text { PAN: } 0.82-1 \mathrm{~m} \text {; MS: } \\
\quad 3.2-4 \mathrm{~m}\end{array}$ & $\begin{array}{l}\text { PAN }(0.49-0.90 \mu \mathrm{m}) ; \text { MS band } \\
1,2,3,4(0.45-0.52 \mu \mathrm{m} ; 0.52-0.60 \\
\mu \mathrm{m} ; 0.63-0.69 \mu \mathrm{m} ; 0.76-0.90 \mu \mathrm{m})\end{array}$ & 14 days (max) \\
\hline OrbView-3 [24] & PAN, MS & 26 June 2003 & PAN: $1 \mathrm{~m} \mathrm{MS:} 4 \mathrm{~m}$ & PAN (1 m); MS (4 m). & 3 day \\
\hline \multicolumn{6}{|c|}{ Medium Resolution Sensor } \\
\hline RADARSAT [69] & SAR & 4 November 1995 & $8-100 \mathrm{~m}(26-328 \mathrm{ft})$ & $\begin{array}{l}\text { RADARSAT-1: Band C (5,3 Ghz); } \\
\text { RADARSAT-2: Band C (5,405 } \\
\text { Ghz) }\end{array}$ & 24 days \\
\hline JERS-1 [73] & $\begin{array}{l}\text {-An L-band SAR; -A } \\
\text { nadir-pointing optical } \\
\text { camera (OPS); -A } \\
\text { side-looking optical } \\
\text { camera (AVNIR). }\end{array}$ & 11 February 1992 & $18 \mathrm{~m}$ & $\begin{array}{c}\text { MS: Band 1,2 }(0.52-0.60 \mu \mathrm{m} ; \\
0.63-0.69 \mu \mathrm{m}) ; \text { NIR band 3,4 } \\
(0.76-0.86 \mu \mathrm{m} ; 0.76-0.86 \mu \mathrm{m}) ; \\
\text { SWIR: Band 5,6,7,8 }(1.60-1.71 \mu \mathrm{m} \text {; } \\
\text { 2.01-2.12 } \mu \mathrm{m} ; 2.13-2.25 \mu \mathrm{m} ; \\
2.27-2.40 \mu \mathrm{m})\end{array}$ & 44 days \\
\hline SENTINEL-1 [74] & $\begin{array}{l}\text { C-synthetic aperture } \\
\text { radar (SAR) }\end{array}$ & April 2014 & $5 \mathrm{~m}$ & Band-C (8400 to $8450 \mathrm{MHz})$ & 6 days \\
\hline LANDSAT 8 [75] & * OLI, * TIRS & February 2013 & $30 \mathrm{~m}$ & $\begin{array}{c}\text { PAN }(0.50-0.67 \mu \mathrm{m}) ; \text { MS } \\
(0.43-0.67 \mu \mathrm{m}) ; \text { NIR }(0.85-0.87 \\
\mu \mathrm{m}) ; \text { SWIR }(1.55-2.2 \mu \mathrm{m}) ; \text { Cirrus } \\
(1.36-1.38 \mu \mathrm{m}) ; \text { Thermal } \\
(10.60-12.51 \mu \mathrm{m}) .\end{array}$ & 16 days \\
\hline
\end{tabular}


Table 3. Cont.

\begin{tabular}{|c|c|c|c|c|c|}
\hline Satellite & Sensor & $\begin{array}{c}\text { Date/ } \\
\text { Decommission }\end{array}$ & $\begin{array}{c}\text { Spatial } \\
\text { Resolution (m) }\end{array}$ & Spectral Resolution & Repeat Cycle (days) \\
\hline Landsat (ETM+) [76] & Opto-mechanical & 15 April 1999 & $30 \mathrm{~m}$ & $\begin{array}{l}\text { MS: Band 1-3 }(0.45 \mathrm{um}-0.69 \mu \mathrm{m}) \text {; } \\
\text { NIR: Band } 4(0.77-0.90 \mu \mathrm{m}) \text {; SWIR: } \\
\text { Band-5,7 }(1.55-1.75,2.09-2.35 \mu \mathrm{m}) \text {; } \\
\text { Thermal: Band-6 }(10.40-12.50 \mu \mathrm{m}) \text {; } \\
\text { PAN: Band } 8(.52-.90 \mu \mathrm{m}) .\end{array}$ & 16 days \\
\hline Landsat 5 [77] & $\mathrm{TM}$ & $\begin{array}{l}\text { March 1984- } \\
\text { January } 2013\end{array}$ & $30 \mathrm{~m}$ & $\begin{array}{l}\text { MS: Band 1-3 }(0.45-0.69 \mu \mathrm{m}) ; \mathrm{NIR} \\
\text { Band 4: }(0.76-0.90 \mu \mathrm{m}) ; \text { SWIR: } \\
\text { Band-5,7 (1.55-1.75, 2.08-2.35); } \\
\text { Thermal: Band-6 (10.40-12.50) }\end{array}$ & 16 \\
\hline \multicolumn{6}{|c|}{ Low Resolution Sensor } \\
\hline MODIS [77] & Aqua/Terra & $\begin{array}{c}18 \text { December } \\
1999\end{array}$ & $1 \mathrm{Km}$ & $\begin{array}{c}36 \text { spectral bands ranging from } 0.4 \\
\mu \mathrm{m} \text { to } 14.4 \mu \mathrm{m} \text { (nd at varying } \\
\text { spatial resolutions ( } 2 \text { bands } \\
0.6 \mu \mathrm{m}-0.9 \mu \mathrm{m}, 5 \text { bands at } \\
0.4 \mu \mathrm{m}-2.1 \mu \mathrm{m} \text { and } 29 \text { bands at } \\
0.4 \mu \mathrm{m}-14.4 \mu \mathrm{m} \text { ) }\end{array}$ & 1 day \\
\hline
\end{tabular}

\subsection{Airborne Imagery}

The very first aerial photograph was taken in 1858 by the French photographer commonly known as Nadar [78]. Since then is has become one of the most important tools for science, engineering and outreach. Aerial imagery portraying flood and storm surge impacts was an important initiative in assessing damage due to hurricane events. Recently, Adams et al. provided a foundation for data collection practices using UAS and their potential for integration with damage assessment techniques using other aerial imagery [79]. Among satellite, aerial and ground based imagery types, each has its own advantages such as breadth for satellite imagery, resolution for aerial imagery and obliqueness for ground based imagery. Advances in UAS technology and its capability for coupling with aerial imagery may decrease overall costs while increasing the usefulness and applicability of the data. This method provides a strong basis for post hurricane event reconnaissance needs [79] due the increased safety compared with putting photographers into the affected area on foot or in ground vehicles. UAS enable flexible data acquisition for required time periods at low cost and is therefore well-suited for targeted monitoring of specific sites while satellite imagery provides the best solution for larger areas [80].

Coastal communities in the southeastern United States have regularly experienced severe hurricane impacts. To better facilitate recovery efforts in these communities following natural disasters, state and federal agencies must respond quickly with information regarding the extent and severity of hurricane damage and the amount of debris volume. To this end, a tool was developed to detect downed trees and debris volume to better aid disaster response efforts and tree debris removal. The tool estimates downed tree debris volume in hurricane affected urban areas using a Leica Airborne Digital Sensor (ADS40, Heerbrugg, Canton St. Gallen, Switzerland) camera and its high resolution digital images [81].

A multi-hazard hurricane event that brings high winds, high precipitation and storm surge complicates the development of robust automated assessment methods. To detect damage resulting from an event, we typically define threshold values selected from the target attribute's data distribution. Jiang and Friedland [82] presented a mono-temporal image classification methodology using IKONOS panchromatic satellite and NOAA aerial color imagery collected in 2005 after Hurricane Katrina. The classification quickly and accurately differentiated urban debris from non-urban debris using post-event images. However, aerial photography in CW studies mostly suffers from limitations due to daylight only acquisition times and weather factors that often accompany storm events such as clouds. Though issues associated with daylight and clouds can be mitigated with flight planning for airborne acquisitions, time sensitive data during storm seasons is likely to be obstructed by clouds resulting radiometric error and data loss [83]. 


\subsection{Low, Moderate and High Spatial Resolution Remote Sensors}

Spatial ground resolution is a measure of the length of the smallest dimension on the Earth's surface that can be captured by the sensor. RS systems with spatial resolution greater than $1 \mathrm{~km}$ are generally classified as low or coarse resolution systems [84]. Coarse resolution and passive RS systems such as MODIS and AVHRR have been used in studies to examine phenomena occurring on scales larger than the ground resolution. For example, MODIS, combined with ecological field studies, Landsat and empirical based models, was used to quantify Hurricane Katrina's impact on U.S. Gulf Coast forests [85]. Mapping large areas impacted by flooding would be feasible by using low resolution data instead of high-resolution data. In a study in India, Jain et al. [86] used NOAA AVHRR data for annual flood monitoring at the river Brahmaputra flowing through the state of Assam (India). The months of July and August were found to be flooded $25-30 \%$ of the time. However, a significant limitation of coarse resolution RS data is spectral similarity between distinctly different features such as dark water and shade [77]. Therefore, utilization of multi-sensor monitoring techniques that can capture both the spatial details of middle-to-high resolution data and the temporal continuity of coarse spatial resolution data is needed to better understand spatio-temporal wetland dynamics.

Imagery with a spatial resolution of 5-100 $\mathrm{m}$ are classified as medium resolution systems [84]. Passive sensors such as Landsat are categorized as medium resolution (on the order of $30 \mathrm{~m}$ ) satellite imagery and have been used in variety of applications such as wetland flood studies and flood model development [69,87-91]. Other medium resolution and passive satellite imagery such as Landsat 5 TM, SPOT 5, Landsat 7 ETM+, ASTER and PALSAR were used to identify storm surge-impacts from Hurricanes Gustav and Ike on Louisiana's wetlands and the interior CWs in southeastern Texas [90]. Robinove [89] used Landsat images to map floods in Queensland, Australia and interpreted dark areas as wet soils rather than flooded regions. In a 2017 study, Sentinel SAR satellite data (10 m resolution) has been used to detect, map and monitor inundation including newly flooded areas and pre-existing water bodies. The flood inundation was assessed in August 2017, four days after Hurricane Harvey made landfall near Houston, Texas as well as the Florida Panhandle and the Florida Keys in September 2017 after Hurricane Irma made landfall as a Category 5 storm [91].

High spatial resolution data ( $5 \mathrm{~m}$ or less) have been available since data from commercial satellite systems became publicly available. Dramatic deformation occurs on coastal areas when coastal storms like hurricanes bring strong winds and waves that alter the topography and near-shore bathymetry of the coast. A study by Seker [92] utilized Interferometric Synthetic Aperture Radar (InSAR) to conduct a spatio-temporal analysis to investigate the effects of strong winds and waves on the coast of Karasu in Black Sea Region of Turkey. InSAR is capable of determining sub-cm level surface deformation under ideal conditions. The analysis showed the distinct changes to the landscape over time. During 2004, two strong tropical cyclones (hurricanes Frances and Jeanne) passed directly over the northern coast of the Bahamas. Comparisons of high resolution $(2.4 \mathrm{~m})$ QuickBird imagery and a quantitative wave model concluded that both the storms had limited effects on the sub-tidal platforms and the storm systems did not significantly alter the system. Instead, daily processes (winds, waves and tides) were determined to be more plausible sources of geomorphic feature alterations [93].

\subsection{Hyperspectral Remote Sensor (HRS)}

Hyperspectral data are obtained using spectrometers that provide complete and continuous spectral information with a large number (224 for AVIRIS) of narrow wavelength bands. Available medium resolution hyperspectral sensors are AVIRIS $(20 \mathrm{~m})$; ALI (30 m); and Hyperion (30 m). Even with many new hyperspectral data available from both commercial and government programs worldwide, the airborne AVIRIS sensor is still considered the most useful hyperspectral sensor [94]. Although orbital sensors such as MODIS, MERIS and ASTER are sometimes classified as hyperspectral, these sensors lack the spatial (MODIS and MERIS) and spectral (ASTER) resolution desired for truly hyperspectral applications [95]. 
As stated previously, Barataria Bay in Louisiana was severely impacted in consecutive years by both the Deepwater Horizon oil spill in 2010 and Hurricane Isaac in 2011. Khanna et al. [45] used AVIRIS hyperspectral imagery over this area just after the oil spill in September 2010, a year later in August 2011 and post-hurricane in October 2012. They found that, after hurricane Isaac, the oiled shorelines (up to the $7 \mathrm{~m}$ topographic contour) experienced a $17.8 \%$, while the land loss on oil-free shorelines was 13.6\%. Zhang [96] combined AVIRIS hyperspectral imagery and Light Detection and Ranging (Lidar) data to map the vegetation of the Florida Everglades. While the combined method produced an overall classification accuracy of $86 \%$ compared to ground truth, the hyperspectral images alone were $76 \%$ accurate. Though not directly related, a similar comparative analysis study of EO-1 ALI/Hyperion and Landsat ETM+ Data for Mapping Forest Crown Closure (CC) and LAI described that the Hyperion sensor outperforms the non-hyperspectral sensors. Hyperion has high spectral resolution including SWIR data which are able to construct optimal VIs that are less affected by the atmosphere. Between ALI and ETM+, ALI performed better for mapping forest CC and LAI since ALI data have more bands and higher signal-to-noise ratios than ETM+ data. The study indicated that Hyperion has the potential for productive before-after analysis of impacts in CW.

Hyperspectral acquisition and analysis is often costly for large areas and can generate large amounts of data to store and process. Due to the variety of sun angles for every flight strip, separate solar and atmospheric adjustments are required in addition to the standard adjustments made to compensate for aircraft pitch, roll and yaw [97].

\subsection{Active Remote Sensors (Radar and Lidar)}

\subsubsection{Radar}

Radar remote sensing is a useful tool for monitoring CWs over large geographic areas due its $30 \mathrm{~m}$ (or better) spatial resolution and ability to penetrate clouds that frequently obscure coastal areas. Chaouch et al. [69] detected inundation between semi-diurnal low and high water conditions using satellite imagery from Radarsat-1 and Landsat along with aerial photography in the northern Gulf of Mexico. The inundation maps were validated using historical aerial photography and achieved a classification accuracy, measured by Probability of Detection (POD) of 83\% [69]. The combination of SAR data and optical images, when coupled with a high resolution $(2 \mathrm{~m})$ digital elevation model, was shown to be useful for inundation mapping and demonstrated potential for the follow-on application of evaluating wetting/drying algorithms in coastal hydrodynamic models. This method was successfully applied to tidal simulation results produced by the ADCIRC model [98]. The differences between modeled and RS derived synoptic inundation extents indicated specific geographic areas in the model where performance was weak and therefore enabled the modelers to make targeted revisions to the input data, especially the terrain characterization [98].

SAR has distinct responses to open water and water with varying emergent vegetation coupled with all-weather capability, making the SAR sensors a promising choice for monitoring wetland ecosystems in storm prone regions with frequent cloud cover. These systems are useful for mapping floods because of their independence from the sun as the illumination source, their all-weather functionality and ability to penetrate forest canopy at certain frequencies and polarizations $[64,99]$. All of these attributes allow SAR systems to provide medium resolution flood inundation extents free of cloud cover contamination compared to Landsat TM or MSS. Imhoff et al. [100] presented SAR imagery as more effective than Landsat MSS for monsoon flood mapping in Bangladesh. Henry et al. [101] used multi-polarized SAR data for flood mapping of Elbe river basin, Central Europe. Horrit et al. [102] delineated flood from the SAR imagery by applying a statistical active contour model. Thus, emergency mapping and flood management is a very useful and practical application of SAR. SAR images have $24 \mathrm{~h}$ (i.e., day or night) capabilities as an active microwave satellite sensor that can penetrate clouds thereby making them valuable for flood monitoring [62] since cloud cover is typically associated with flood events. 


\subsubsection{Lidar}

Lidar is an RS technology used mainly to conduct topographic surveys [103-105] from an airborne platform. It measures the range between the target and the sensor using a pulsed laser. Lidar is useful to estimate the threat of SLR to coastal ecosystems and also to analyze the intensity and level of impact from raised water elevation and salt water penetration to coastal ecosystems [106]. For example, Huang et al. [107] monitored wetland inundation using Landsat and Lidar data. Lidar is also useful for detecting water surfaces, even small channels, due to its fine spatial resolution and strong absorption of light energy by water surfaces. Integrating Lidar elevations and signal intensity of ground returns were utilized to map the wet channel networks of several watersheds near Lake Tahoe [108].

Lidar is known for its ability to cover large geographic locations at a relatively low cost compared to traditional land surveying. Digital Elevation Models (DEMs) derived from Lidar are generally recognized to produce topographic surfaces that are accurate enough for a variety of modeling, mapping and civil engineering applications [104]. Real Time Kinematic (RTK) topographic survey data still outperforms Lidar in terms of vertical accuracy, especially in areas of dense low vegetation such as coastal marshes [104,105]. This is mainly due to the inability of the laser to penetrate the marsh grasses and reflect off of the true marsh surface. In addition, raw (unadjusted) Lidar intensity data are usually incomparable between Lidar collections and are sensitive to the angle at which the laser interacts with ground surface [109].

\section{Future Wetland Remote Sensing Studies}

Future opportunities for RS research in CW will involve both maximum utilization of existing high resolution sensors such as Hyperion and investigation / development of new sensors. There is both significant potential and emerging environmental challenges that RS is suitable to address such as the global monitoring of mangrove forests, the ecological effects of SLR [104] and the progress and effectiveness of restoration efforts. There is also potential for future studies in finding both spatial and temporal changes in ecosystems and linking them with global/regional climatic or hydrologic events. Alongside these potential RS based advances, innovative ground truth techniques that validate them will also be necessary.

\subsection{Algorithms for Multi Sensor Integrations in Wetland Studies}

Remote sensing has been used widely for wetland classification for more than 50 years, achieving a wide range of effectiveness. Some have used single source data such as photography, medium-resolution images, high-resolution images [110], hyperspectral images [111], radar and lidar data $[108,112]$ with conventional or improved methods of data mining to model or classify wetland ecosystems. Others used a combination of RS and field survey data for the same purpose [104]. A few studies suggested that integrating different data sources can increase the classification accuracy $[113,114]$. Integration is especially useful when sensor types such as combining optical images with radar or Lidar data. Additionally, multi-season RS can increase classification accuracy [75] by presenting data for the same location in two or more phenological states. Scientists and engineers must be rigorous when combining sensor data from different time periods to detect expected (growth, color change) and unexpected (land clearing, storm damage) effects. All areas with emergent vegetation, such as wetlands, have high heterogeneity in reflectance due to water level, turbidity and vegetation density (for example), so merging data acquired at different times needs careful attention and defensible/reproducible methods with transparent parameter selection based on plausible physical factors. Development of validated algorithms for unifying different spatio-temporal resolution sensors to a common basis would be a useful tool for RS studies, especially those of wetlands. 


\subsection{Large Spatial Scales}

A very few past studies have focused on using remote sensors on a global scale. Hydrologic impacts and changes to ecosystems are better understood at larger spatial scales. Since global scale studies require onerous data collection and management processes, they tend to be very expensive which necessitates choosing imagery carefully to meet the objective under budget and computational constraints. Generally, low resolution images are used only when a gross level of vegetation classes is sufficient, whereas higher resolution images are used for fine vegetation classifications. Therefore, both from mapping scale point of view and cost efficiency, vegetation mapping at local/small scale generally needs high-resolution images, while low-resolution images are used for a large-scale mapping. MODIS data are a common source of coarse-resolution data that have the capability to map global wetland change. MODIS derived secondary data have been used in several studies mentioned previously. Radar RS offers a global perspective for several hydrological parameters. The all-weather capable satellite radar altimetry is used to delineate water bodies and wetland levels and infrared imagery can be used to detect visible wet areas. A program to globally and continuously monitor all large inland water bodies at the Mullard Space Science Laboratory showed an accuracy of $5 \mathrm{~cm}$ root mean square (RMS) of these waterbodies level variation [115]. The development of ScanSAR technologies made it possible to monitor the impact of climate change in permafrost transition zones. For example, using ENVISAT ASAR Global mode (GM, $1 \mathrm{~km}$ resolution), climate and environmental data (up to 2012) from boreal environments are available for research and analysis. Research as identified up to $75 \%$ of oligotrophic bogs in the seasonal permafrost zone [116]. Also, the high seasonal and inter-annual dynamics of the sub-tropic Okavango Delta in Botswana, Africa, were captured by GM time series [116].

Although the understanding and quantifying of wetland dynamics has been advanced, the validation of large scale wetland monitoring is still challenging and needs to be extended using auxiliary data from secondary sources such as in-situ measurement and unmanned aerial vehicles. Coarse-resolution can be used to globally map wetlands using the decomposition of mixed pixel technology [11]. For example, MODIS coarse-resolution data and their derived vegetation indices can map global wetland changes. High performance computing opens many opportunities for fine resolution classification, prediction of missing/obstructed wetland hydrologic data and modeling wetland hydrology temporal dynamics.

\subsection{New Data and Methods}

The prime weakness of optical data is the data loss due to clouds, haze and shadows. In some regions, especially coastal areas, clouds and rain events are frequent and these wet periods are important for plant growth and aquatic ecosystem balance. During this period, hydrologic events such as storms, hurricanes and high precipitation occur and the need of large spatial coverage using RS arises to monitor the intensity of these hydrologic events and subsequent vegetation change. However, while the objectives may be clear, difficulties can still occur. For example, the optical sensor on board Landsat 7 occasionally showed anomalies such as Late Start Anomalies (LSAs) that was observed from 2006 to April 2007. Then, Landsat 7 switched to bumper mode and the LSAs cannot occur in bumper mode and the problem resolved. Another issue with optical images is that they usually fail to monitor vegetation types within wetlands because the dense vegetation cover leads to signal saturation. Previous studies explored several methods as well as different sensors to overcome these limitations. To mitigate the data loss due to cloud cover, the Optical Cloud Pixel Recovery (OCPR) method was developed [110] to repair missing remote sensor pixels using information from the time-space-spectrum continuum. Using a Random Forest (RF) model trained using over fifteen years of Landsat imagery and local hydrologic data, NDVI values for cloud obscured pixels were able to be recovered with sufficient accuracy so that images that would have been previously discarded can now be used in the long term time series. The OCPR model performed well in a dynamic wetland ecosystem in the northern Gulf of Mexico. If optical images are obstructed by clouds, they are unable to accurately describe the extent of saturated areas in wetlands. Marechal et al. [117] overcame this by 
employing time series Radarsat-2 data to monitor the seasonal changes of wetlands using SAR data and new supervised PolSAR segmentation methods, taking advantage of the radar data's ability to penetrate clouds.

Landsat 8, launched in 2013 is the most evolved platform of the Landsat lineage. Landsat 9 is planned to be launched in 2020 and will continue to evolve as did Landsat 8 . Both Landsat 8 and 9 have the Operational Land Imager (OLI) and the Thermal Infrared Sensor (TIRS) [118]. Landsat 8 has further capabilities to investigate water resources and for the detection of cirrus clouds and also provides information on the presence of features such as clouds, water and snow. The innovative designs of Landsat 8 and Landsat 9 make them more sensitive and more reliable than earlier Landsat satellites. They can be used to detect more subtle details in the images. The multispectral sensors on board Landsat 8 and Sentinel-2 offer the possibility to perform high-frequency time series analyses. They have the potential to carry out multi-temporal change detection before and after significant events such as mapping for disaster management. The end user must still pay particular attention to the impact of the radiometric differences between the images (Landsat 8 and Sentinel-2) acquired by the two sensors [119]. Though both of the sensor's radiometric accuracies are high, the difference still requires careful evaluation to determine whether the differences in reflectance values are relevant and fulfill the purpose of the specific application. Sentinel-3 (launched at February 2016; design life: 7 years) is considered the most improved version of the family of Sentinel satellites. The Sentinel system first launched in 2014 resulted in an exceptional blend of spatial resolution, spectral coverage and temporal revisit time. Sentinel-3 has even greater potential to enhance water quality assessment, eutrophication monitoring and plant / crop health monitoring [120]. Newer data from various remote sensors on board of many different platforms and of different types will continue to be leveraged to produce more robust methods utilizing longer time series.

\section{Summary and Conclusions}

This paper provides an overview of RS applications in assessing the impact of EHEs in CWs. Coastal wetlands worldwide have been experiencing significant threats due to EHEs. Sea level rise, intensified storms and changing freshwater input, along with human impacts, directly impact CWs and limit their ability to provide valuable ecosystem services. The usefulness of vegetation indices and other methods for identifying the impact on CWs is the primary focus of the current review paper.

Remote sensors were categorized according to their ground resolutions: Coarse, medium and high. Hyperspectral images are a unique case and have a range of ground resolutions along with their fine spectral resolution. Also, remote sensors typically used in this application were categorized as active and passive according to their source of electromagnetic radiation. Satellite/aerial photography is also an integral part of sensor systems used to monitor and assess hydrologic impacts and in recent years, aerial photography has been used in conjunction with unmanned aerial systems to assess post storm damage and classify different types of CWs. Depending on the areal extent and purpose of a particular study, investigators blend a variety of sensor data that adequately captures the spatial, spectral and time scales relevant to the target wetland and hazard types. Often times, abstracted indices, such as Normalized difference vegetation index, derived from MODIS, LANDSAT and/or AVHRR are frequently used in coastal wetland studies. Hyperspectral data are used mostly in relatively small area studies due their advantage of deep spectral resolution and also their high cost and data magnitude. Active sensors such as synthetic aperture radar consistently outperformed optical sensors in coastal wetland change detection because of its ability to penetrate clouds and canopy. lidar data have also been shown to be very useful for monitoring and exploring ground surface and elevation information such as the height of forests or the water level. Many studies use lidar in combination with other forms of RS data to amplify the classification and quantification effectiveness.

This study documented previous researches on the application of RS with special focus on vegetation indices to identify and assess the impacts of EHEs on CWs. The discussion aimed to identify limitations and advantages of certain vegetation indices and also primary sensor data in an effort to 
guide future research into this application of RS. This study also discussed potential future research topics for enhancing coastal wetland studies using RS. Thus, this paper provides a reference base for future studies involving long term monitoring of CWs, especially their response to EHEs.

Author Contributions: S.T. conducted the literature review and prepared the manuscript. S.C.M. supervised the remote sensing related and coastal wetland research and reviewed the manuscript for style, content and grammar. A.S. reviewed the manuscript for structure and guided the literature review and graphics preparation.

Funding: This research was funded by the National Oceanic and Atmospheric Administration (NOAA) Ecological Effects of Sea Level Rise (EESLR) Program under grant number NA16NOS4780208.

Acknowledgments: A.S. acknowledges support from Tsinghua University and the Donors of the American Chemical Society Petroleum Research Fund. The data presented in this paper is publicly available.

Conflicts of Interest: The authors declare no conflicts of interest.

\section{References}

1. Michener, W.K.; Blood, E.R.; Bildstein, K.L.; Brinson, M.M.; Gardner, L.R. Climate change, hurricanes and tropical storms, and rising sea level in coastal wetlands. Ecol. Appl. 1997, 7, 770-801. [CrossRef]

2. Hardisky, M.A.; Gross, M.F.; Klemas, V. Remote Sensing of Coastal Wetlands. Bioscience 1986, 36, 453-460. [CrossRef]

3. Webb, E.L.; Friess, D.A.; Krauss, K.W.; Cahoon, D.R.; Guntenspergen, G.R.; Phelps, J. A global standard for monitoring coastal wetland vulnerability to accelerated sea-level rise. Nat. Clim. Chang. 2013, 3, 458. [CrossRef]

4. Chen, X.; Zong, Y.; Zhang, E.; Xu, J.; Li, S. Human impacts on the Changjiang (Yangtze) River basin, China, with special reference to the impacts on the dry season water discharges into the sea. Geomorphology 2001, 41, 111-123. [CrossRef]

5. Huang, Y.; Sun, W.; Zhang, W.; Yu, Y.; Su, Y.; Songw, C. Marshland conversion to cropland in northeast China from 1950 to 2000 reduced the greenhouse effect. Glob. Chang. Biol. 2010, 16, 680-695. [CrossRef]

6. Langley, J.A.; Megonigal, J.P. Ecosystem response to elevated $\mathrm{CO}_{2}$ levels limited by nitrogen-induced plant species shift. Nature 2010, 466, 96. [CrossRef] [PubMed]

7. Barbier, E.B.; Hacker, S.D.; Kennedy, C.; Koch, E.W.; Stier, A.C.; Silliman, B.R. The value of estuarine and coastal ecosystem services. Ecol. Monogr. 2011, 81, 169-193. [CrossRef]

8. Ericson, J.P.; Vörösmarty, C.J.; Dingman, S.L.; Ward, L.G.; Meybeck, M. Effective sea-level rise and deltas: Causes of change and human dimension implications. Glob. Planet. Chang. 2006, 50, 63-82. [CrossRef]

9. Yu, J.; Zhan, C.; Li, Y.; Zhou, D.; Fu, Y.; Chu, X.; Xing, Q.; Han, G.; Wang, G.; Guan, B.; et al. Distribution of Carbon, Nitrogen and Phosphorus in Coastal Wetland Soil Related Land Use in the Modern Yellow River Delta. Sci. Rep. 2016, 6, 37940. [CrossRef] [PubMed]

10. White, E.; Kaplan, D. Restore or retreat? Saltwater intrusion and water management in coastal wetlands. Ecosyst. Heal. Sustain. 2017, 3, 1258. [CrossRef]

11. Guo, M.; Li, J.; Sheng, C.; Xu, J.; Wu, L. A review of wetland remote sensing. Sensors 2017, 17, 777. [CrossRef] [PubMed]

12. Sandhu, D.; Singh, A.; Fan, N.; Wang, D.; Duranceau, S.J. Hydro-geomorphic response of Everglades to changing climate and anthropogenic activities. J. Hydrol. 2016, 543, 861-872. [CrossRef]

13. Konisky, D.M.; Hughes, L.; Kaylor, C.H. Extreme weather events and climate change concern. Clim. Chang. 2016, 134, 533-547. [CrossRef]

14. Schubel, J.R.; Hirschberg, D.J. Estuarine Graveyards, Climatic Change, and the Importance of the Estuarine Environment. In Estuarine Interactions; Academic Press: New York, NY, USA, 1978; pp. 285-303.

15. Scavia, D.; Field, J.C.; Boesch, D.F.; Buddenmeier, R.W.; Burkett, V.; Cayan, D.R.; Fogarty, M.; Harwell, M.A.; Howarth, R.W.; Mason, C.; et al. Climate Change Impacts on U.S. Coastal and Marine Ecosystems. Estuaries 2002, 25, 149-164. [CrossRef]

16. Ozesmi, S.L.; Bauer, M.E.; Tiner, R.W.; Lang, M.W.; Klemas, V. V Satellite remote sensing of wetlands. Wetl. Ecol. Manag. 2002, 5, 381-402. [CrossRef]

17. Wilcox, D.A.; Whillans, T.H. Techniques for restoration of disturbed coastal wetlands of the Great Lakes. Wetlands 1999, 19, 835-857. [CrossRef] 
18. Day, J.W.; Christian, R.; Boesch, D.M.; Yáñez-Arancibia, A.; Morris, J.; Twilley, R.; Naylor, L.; Schaffner, L.; Stevenson, C. Consequences of climate change on the ecogeomorphology of coastal wetlands. Estuaries Coasts 2008, 31, 477-491. [CrossRef]

19. Nicholls, R.J.; Cazenave, A. Sea-level rise and its impact on coastal zones. Science 2010, 328, 1517-1520. [CrossRef] [PubMed]

20. Tahsin, S.; Medeiros, C.S.; Singh, A. Resilience of coastal wetlands to extreme hydrologic events in Apalachicola Bay. Geophys. Res. Lett. 2016, 43, 7529-7537. [CrossRef]

21. Cahoon, D.R.; Reed, D.J.; Day, J.W., Jr.; Steyer, G.D.; Boumans, R.M.; Lynch, J.C.; McNally, D.; Latif, N. The influence of Hurricane Andrew on sediment distribution in Louisiana coastal marshes. J. Coast. Res. 1995, 1995, 280-294.

22. Reed, D.J. The response of coastal marshes to sea-level rise: Survival or submergence? Earth Surf. Process. Landf. 1995, 20, 39-48. [CrossRef]

23. Goodbred, S.L.; Wright, E.E.; Hine, A.C. Sea-level change and storm-surge deposition in a late Holocene Florida salt marsh. J. Sediment. Res. 1998, 68, 240-252. [CrossRef]

24. Klemas, V. Using Remote Sensing to Select and Monitor Wetland Restoration Sites: An Overview. J. Coast. Res. 2013, 29, 958-970. [CrossRef]

25. Kentula, M.E. Wetland Restoration and Creation. Natl. Water Summ. Wetl. Resour. 2015, 2425, 87-92.

26. Xue, J.; Su, B. Significant remote sensing vegetation indices: A review of developments and applications. J. Sens. 2017, 2017, 1353691. [CrossRef]

27. Honkavaara, E.; Saari, H.; Kaivosoja, J.; Pölönen, I.; Hakala, T.; Litkey, P.; Mäkynen, J.; Pesonen, L. Processing and assessment of spectrometric, stereoscopic imagery collected using a lightweight UAV spectral camera for precision agriculture. Remote. Sens. 2013, 5, 5006-5039. [CrossRef]

28. Karnieli, A.; Agam, N.; Pinker, R.T.; Anderson, M.; Imhoff, M.L.; Gutman, G.G.; Panov, N.; Goldberg, A. Use of NDVI and land surface temperature for drought assessment: Merits and limitations. J. Clim. 2010, 23, 618-633. [CrossRef]

29. Major, D.J.; Baret, F.; Guyot, G. A ratio vegetation index adjusted for soil brightness. Int. J. Remote. Sens. 1990, 11, 727-740. [CrossRef]

30. Rodgers, J.C.; Murrah, A.W.; Cooke, W.H. The impact of Hurricane Katrina on the coastal vegetation of the Weeks Bay Reserve, Alabama from NDVI data. Estuaries Coasts 2009, 32, 496-507. [CrossRef]

31. Ramsey, E.W., III; Chappell, D.K.; Baldwin, D.G. AVHRR lmagery Used to Identify Hurricane Damage in a Forested Wetland of Louisiana. Photogramm. Eng. Remote. Sens. 1997, 63, 293-297.

32. Ramsey, I.; Spruce, J.; Rangoonwala, A.; Suzuoki, Y.; Smoot, J.; Gasser, J.; Bannister, T. Daily MODIS data trends of hurricane-induced forest impact and early recovery. Photogramm. Eng. Remote. Sens. 2011, 17, 1113-1143. [CrossRef]

33. Wang, Y. Detecting Vegetation Recovery Patterns After Hurricanes in South Florida Using NDVI Time Series. Master's Thesis, University of Miami, Coral Gables, FL, USA, 2012.

34. Mo, Y.; Kearney, M.S.; Riter, J.C.A.; Zhao, F.; Tilley, D.R. Assessing biomass of diverse coastal marsh ecosystems using statistical and machine learning models. Int. J. Appl. Earth Obs. Geoinf. 2018, 68, 189-201. [CrossRef]

35. Hatter, L. Apalachicola Bay Part 2: Climate Change and Collapse. Available online: http://news.wfsu.org/ post/apalachicola-bay-part-2-climate-change-and-collapse (accessed on 30 October 2015).

36. Leitman, S.; Pine, W.E.; Kiker, G. Management Options during the 2011-2012 Drought on the Apalachicola River: A Systems Dynamic Model Evaluation. Environ. Manag. 2016, 58, 193-207. [CrossRef] [PubMed]

37. Justice, C.O.; Vermote, E.F.; Townshend, J.R.G.; Defries, R.S.; Roy, D.P.; Hall, D.K.; Salomonson, V.V.; Privette, J.L.; Riggs, G.; Strahler, A.H.; et al. The Moderate Resolution Imaging Spectroradiometer (MODIS): Land remote sensing for global change research. IEEE Trans. Geosci. Remote. Sens. 1998, 36, 1228-1249. [CrossRef]

38. Feng, Y.; Negron-juarez, R.I.; Patricola, C.M.; Collins, W.D.; Uriarte, M.; Hall, J.S.; Clinton, N.; Chambers, J.Q. Rapid remote sensing assessment of impacts from Hurricane Maria on forests of Puerto Rico. PeerJ Prepr. 2018, 6, 26597.

39. Wang, F.; D'Sa, E.J. Potential of MODIS EVI in identifying hurricane disturbance to coastal vegetation in the Northern Gulf of Mexico. Remote. Sens. 2010, 2, 1-18. [CrossRef] 
40. Rogan, J.; Schneider, L.; Christman, Z.; Millones, M.; Lawrence, D.; Schmook, B. Hurricane disturbance mapping using MODIS EVI data in the southeastern Yucatán, Mexico. Remote. Sens. Lett. 2011, 2, $259-267$. [CrossRef]

41. Sesnie, S.E.; Dickson, B.G.; Rosenstock, S.S.; Rundall, J.M. A comparison of Landsat TM and MODIS vegetation indices for estimating forage phenology in desert bighorn sheep (ovis canadensis nelsoni) habitat in the Sonoran desert, USA. Int. J. Remote. Sens. 2012, 33, 276-286. [CrossRef]

42. Matsushita, B.; Yang, W.; Chen, J.; Onda, Y.; Qiu, G. Sensitivity of the Enhanced Vegetation Index (EVI) and Normalized Difference Vegetation Index (NDVI) to topographic effects: A case study in high-density cypress forest. Sensors 2007, 7, 2636-2651. [CrossRef] [PubMed]

43. Huete, A.R. A soil-adjusted vegetation index (SAVI). Remote. Sens. Environ. 1988, 25, 295-309. [CrossRef]

44. Byrd, K.B.; Ballanti, L.; Thomas, N.; Nguyen, D.; Holmquist, J.R.; Simard, M.; Windham-Myers, L. A remote sensing-based model of tidal marsh aboveground carbon stocks for the conterminous United States. ISPRS J. Photogramm. Remote. Sens. 2018, 139, 255-271. [CrossRef]

45. Khanna, S.; Santos, M.J.; Koltunov, A.; Shapiro, K.D.; Lay, M.; Ustin, S.L. Marsh Loss Due to Cumulative Impacts of Hurricane Isaac and the DeepWater Horizon Oil Spill in Louisiana. Remote. Sens. 2017, 9, 169. [CrossRef]

46. Wang, W.; Qu, J.J.; Hao, X.; Liu, Y.; Stanturf, J.A. Post-hurricane forest damage assessment using satellite remote sensing. Agric. For. Meteorol. 2010, 150, 122-132. [CrossRef]

47. Orville, H.D. AMS statement on meteorological drought. Bull. Am. Meteorol. Soc. 1990, 71, $1021-1023$. [CrossRef]

48. Quiring, S.M. Monitoring drought: An evaluation of meteorological drought indices. Geogr. Compass 2009, 3, 64-88. [CrossRef]

49. Quiring, S.M.; Ganesh, S. Evaluating the utility of the Vegetation Condition Index (VCI) for monitoring meteorological drought in Texas. Agric. For. Meteorol. 2010, 150, 330-339. [CrossRef]

50. Ji, L.; Peters, A.J. Assessing vegetation response to drought in the northern Great Plains using vegetation and drought indices. Remote. Sens. Environ. 2003, 87, 85-98. [CrossRef]

51. Seiler, R.A.; Kogan, F.; Wei, G. Monitoring weather impact and crop yield from NOAA AVHRR data in Argentina. Adv. Space Res. 2000, 26, 1177-1185. [CrossRef]

52. Kogan, F.N. Droughts of the Late 1980s in the United States as Derived from NOAA Polar-Orbiting Satellite Data. Bull. Am. Meteorol. Soc. 1995, 76, 655-668. [CrossRef]

53. Jiao, W.; Zhang, L.; Chang, Q.; Fu, D.; Cen, Y.; Tong, Q. Evaluating an enhanced vegetation condition index (VCI) based on VIUPD for drought monitoring in the continental United States. Remote. Sens. 2016, 8, 224. [CrossRef]

54. Mo, Y.; Kearney, M.; Momen, B. Drought-associated phenological changes of coastal marshes in Louisiana. Ecosphere 2017, 8. [CrossRef]

55. Chapple, D.; Dronova, I. Vegetation Development in a Tidal Marsh Restoration Project during a Historic Drought: A Remote Sensing Approach. Front. Mar. Sci. 2017. [CrossRef]

56. Sruthi, S.; Aslam, M.A.M. Agricultural Drought Analysis Using the NDVI and Land Surface Temperature Data; a Case Study of Raichur District. Aquat. Procedia 2015, 4, 1258-1264. [CrossRef]

57. Zhang, X.; Yamaguchi, Y.; Li, F.; He, B.; Chen, Y. Assessing the Impacts of the 2009/2010 Drought on Vegetation Indices, Normalized Difference Water Index, and Land Surface Temperature in Southwestern China. Adv. Meteorol. 2017, 2017, 6837493. [CrossRef]

58. Waite, W.P.; Macdonald, H.C. “Vegetation Penetration” With K-Band Imaging Radars. IEEE Trans. Geosci. Electron. 1971, 9, 147-155. [CrossRef]

59. Bourgeau-Chavez, L.L.; Smith, K.B.; Brunzell, S.M.; Kasischke, E.S.; Romanowicz, E.A.; Richardson, C.J. Remote monitoring of regional inundation patterns and hydroperiod in the Greater Everglades using Synthetic Aperture Radar. Wetlands 2005, 25, 176-191. [CrossRef]

60. Costa, M.P.F. Use of SAR satellites for mapping zonation of vegetation communities in the Amazon floodplain. Int. J. Remote Sens. 2004, 25, 1817-1835. [CrossRef]

61. Costa, M.P.F.; Niemann, O.; Novo, E.; Ahern, F. Biophysical properties and mapping of aquatic vegetation during the hydrological cycle of the Amazon floodplain using JERS-1 and Radarsat. Int. J. Remote Sens. 2002, 23, 1401-1426. [CrossRef] 
62. Grings, F.M.; Ferrazzoli, P.; Jacobo-Berlles, J.C.; Karszenbaum, H.; Tiffenberg, J.; Pratolongo, P.; Kandus, P. Monitoring flood condition in marshes using EM models and Envisat ASAR observations. IEEE Trans. Geosci. Remote Sens. 2006, 44, 936-942. [CrossRef]

63. Hess, L.L.; Melack, J.M.; Melack, J.M.; Filoso, S.; Wang, Y.; Wang, Y. Delineation of Inundated Area and Vegetation Along the Amazon Floodplain with the SIR-C Synthetic Aperture Radar. IEEE Trans. Geosci. Remote Sens. 1995, 33, 896-904. [CrossRef]

64. Kiage, L.M.; Walker, N.D.; Balasubramanian, S.; Babin, A.; Barras, J. Applications of Radarsat-1 synthetic aperture radar imagery to assess hurricane-related flooding of coastal Louisiana. Int. J. Remote Sens. 2005, 26, 5359-5380. [CrossRef]

65. Rykhus, R.; Lu, Z. Hurricane Katrina Flooding and Oil Slicks Mapped with Satellite Imagery; U.S. Geological Survey: Reston, VA, USA, 2005.

66. Jain, S.K.; Singh, R.D.; Jain, M.K.; Lohani, A.K. Delineation of flood-prone areas using remote sensing techniques. Water Resour. Manag. 2005, 19, 333-347. [CrossRef]

67. Thomas, R.F.; Kingsford, R.T.; Lu, Y.; Cox, S.J.; Sims, N.C.; Hunter, S.J. Mapping inundation in the heterogeneous floodplain wetlands of the Macquarie Marshes, using Landsat Thematic Mapper. J. Hydrol. 2015, 524, 194-213. [CrossRef]

68. Ho, L.T.K.; Umitsu, M.; Yamaguchi, Y. Flood hazard mapping by satellite images and SRTM DEM in the Vu Gia-Thu Bon alluvial plain, Central Vietnam. Int. Arch. Photogramm. Remote Sens. Spat. Inf. Sci. 2010, 38, 275-280.

69. Chaouch, N.; Temimi, M.; Hagen, S.; Weishampel, J.; Medeiros, S.; Khanbilvardi, R. A synergetic use of satellite imagery from SAR and optical sensors to improve coastal flood mapping in the Gulf of Mexico. Hydrol. Process. 2012, 26, 1617-1628. [CrossRef]

70. Hassan, N.; Hamid, J.R.A.; Adnan, N.A.; Jaafar, M. Delineation of wetland areas from high resolution WorldView-2 data by object-based method. In IOP Conference Series: Earth and Environmental Science; IOP Publishing Ltd.: Bristol, UK, 2014; Volume 18, p. 012017.

71. Kumar, L.; Sinha, P. Mapping salt-marsh land-cover vegetation using high-spatial and hyperspectral satellite data to assist wetland inventory. GIScience Remote. Sens. 2014, 51, 483-497. [CrossRef]

72. Jollineau, M.; Howarth, P. Use of high-resolution imagery to map wetland environments in south-central Ontario, Canada. In Proceedings of the IEEE International Geoscience and Remote Sensing Symposium, Toronto, ON, Canada, 24-28 June 2002; pp. 3089-3091.

73. Jung, H.C. Wetland Hydrodynamics Using Interferometric Synthetic Aperture Radar, Remote Sensing, and Modeling. Ph.D. Thesis, The Ohio State University, Columbus, OH, USA, 2011.

74. Muro, J.; Canty, M.; Conradsen, K.; Hüttich, C.; Nielsen, A.A.; Skriver, H.; Remy, F.; Strauch, A.; Thonfeld, F.; Menz, G. Short-term change detection in wetlands using Sentinel-1 time series. Remote Sens. 2016, 8, 795. [CrossRef]

75. Wu, W.-T.; Zhou, Y.-X.; Tian, B. Coastal wetlands facing climate change and anthropogenic activities: A remote sensing analysis and modelling application. Ocean Coast. Manag. 2017, 138, 1-10. [CrossRef]

76. Mueller, N.; Lewis, A.; Roberts, D.; Ring, S.; Melrose, R.; Sixsmith, J.; Lymburner, L.; McIntyre, A.; Tan, P.; Curnow, S.; et al. Water observations from space: Mapping surface water from 25 years of Landsat imagery across Australia. Remote Sens. Environ. 2016, 174, 341-352. [CrossRef]

77. Michishita, R.; Gong, P.; Xu, B. Spectral mixture analysis for bi-sensor wetland mapping using Landsat TM and Terra MODIS data. Int. J. Remote Sens. 2012, 33, 3373-3401. [CrossRef]

78. Aber, J. Lighter-than-air Platforms for Small-format Aerial Photography. Trans. Kans. Acad. Sci. 2004, 33, 3373-3401. [CrossRef]

79. Adams, S.M.; Friedland, C.J.; Levitanc, M.L. Unmanned Aerial Vehicle Data Acquisition for Damage Assessment in Hurricane Events. In Proceedings of the 8th International Workshop on Remote Sensing for Disaster Management, Tokyo, Japan, 30 September-1 October 2010; Volume 30.

80. Müllerová, J.; Brůna, J.; Bartaloš, T.; Dvořák, P.; Vítková, M.; Pyšek, P. Timing Is Important: Unmanned Aircraft vs. Satellite Imagery in Plant Invasion Monitoring. Front. Plant Sci. 2017, 8, 887. [CrossRef] [PubMed]

81. Szantoi, Z.; Malone, S.; Escobedo, F.; Misas, O.; Smith, S.; Dewitt, B. A tool for rapid post-hurricane urban tree debris estimates using high resolution aerial imagery. Int. J. Appl. Earth Obs. Geoinf. 2012, 18, 548-556. [CrossRef] 
82. Jiang, S.; Friedland, C.J. Automatic urban debris zone extraction from post-hurricane very high-resolution satellite and aerial imagery. Geomat. Nat. Hazards Risk 2016, 7, 933-952. [CrossRef]

83. Morgan, J.L.; Gergel, S.E.; Coops, N.C. Aerial Photography: A Rapidly Evolving Tool for Ecological Management. Bioscience 2010, 60, 47-59. [CrossRef]

84. Campbell, J.B. Introduction to Remote Sensing, 2nd ed.; The Guilford Press: New York, NY, USA, 1996; ISBN 0748406638.

85. Chambers, J.Q.; Fisher, J.I.; Zeng, H.; Chapman, E.L.; Baker, D.B.; Hurtt, G.C. Hurricane Katrina's carbon footprint on U.S. Gulf Coast forests. Science 2007, 318, 1107. [CrossRef] [PubMed]

86. Jain, S.K.; Saraf, A.K.; Goswami, A.; Ahmad, T. Flood inundation mapping using NOAA AVHRR data. Water Resour. Manag. 2006, 20, 949-959. [CrossRef]

87. Wang, Y.; Colby, J.D.; Mulcahy, K.A. An efficient method for mapping flood extent in a coastal floodplain using Landsat TM and DEM data. Int. J. Remote. Sens. 2002, 23, 3681-3696. [CrossRef]

88. Todhunter, P.E.; Rundquist, B.C. Terminal Lake Flooding and Wetland Expansion in Nelson County, North Dakota. Phys. Geogr. 2004, 25, 68-85. [CrossRef]

89. Robinove, C.J. Interpretation of a Landsat image of an unusual flood phenomenon in Australia. Remote. Sens. Environ. 1978, 7, 219-225. [CrossRef]

90. Barras, J.A.; Brock, J.C.; Morton, R.A.; Travers, L.J. Remotely Sensed Imagery Revealing the Effects of Hurricanes Gustav and Ike on Coastal Louisiana, 2008; U.S. Geological Survey: Reston, VA, USA, 2010.

91. Nghiem, S.V.; Brakenridge, G.R.; Nguyen, D.T. Hurricanes Harvey and Irma-High-Resolution Flood Mapping and Monitoring from Sentinel SAR with the Depolarization Reduction Algorithm for Global Observations of InundatioN (DRAGON); American Geophysical Union: Washington, DC, USA, 2017.

92. Seker, D.Z.; Direk, S.; Musaoglu, N.; Gazioglu, C. Determination of Effects of Coastal Deformation Caused by Waves and Storms at Black Sea Coast of Turkey Utilizing InSAR Technique; American Geophysical Union: Washington, DC, USA, 2013.

93. Reeder, S.L.; Rankey, E.C. A Tale of Two Storms: An Integrated Field, Remote Sensing, and Modeling Study Examining the Impact of Hurricanes Frances and Jeanne on Carbonate Systems, Bahamas; Swart, P.K., Eberli, G.P., McKenzie, J.A., Jarvis, I., Stevens, T., Eds.; International Association of Sedimentologists: Ghent, Belgium, 2009; ISBN 9781444312065.

94. Goetz, A.F.H. Three decades of hyperspectral remote sensing of the Earth: A personal view. Remote Sens. Environ. 2009, 113, S5-S16. [CrossRef]

95. Dor, E.B.; Malthus, T.; Plaza, A.; Schläpfer, D. Hyperspectral Remote Sensing; SPIE: Bellingham, WA, USA, 2012; ISBN 9780819487872.

96. Zhang, H.; Chen, J.M.; Huang, B.; Song, H.; Li, Y. Reconstructing Seasonal Variation of Landsat Vegetation Index Related to Leaf Area Index by Fusing with MODIS Data. IEEE J. Sel. Top. Appl. Earth Obs. Remote. Sens. 2014, 7, 891-901. [CrossRef]

97. Porter, D.E.; Field, D.W.; Klemas, V.V.; Jensen, J.R.; Malhotra, A.; Field, R.T.; Walker, S.P. RESAAP Final Report: NOAA/NERRS Remote Sensing Applications Assessment Project; University of South Carolina: Columbia, SC, USA, 2006.

98. Medeiros, S.C.; Hagen, S.C. Review of wetting and drying algorithms for numerical tidal flow models. Int. J. Numer. Methods Fluids 2013, 71, 473-487. [CrossRef]

99. Townsend, P.A. Relationships between forest structure and the detection of flood inundation in forested wetlands using C-band SAR. Int. J. Remote Sens. 2002, 23, 443-460. [CrossRef]

100. Imhoff, M.L.; Vermillon, C.; Story, M.H.; Choudhury, M.A.; Gafoor, A. Monsoon flood boundary delineation and damage assessment using space borne imaging radar and Landsat data. Photogramm. Eng. Remote Sens. 1987, 53, 405-413.

101. Henry, J.B.; Chastanet, P.; Fellah, K.; Desnos, Y.L. Envisat multi-polarized ASAR data for flood mapping. Int. J. Remote Sens. 2006, 27, 1921-1929. [CrossRef]

102. Horritt, M.S.; Mason, D.C.; Luckman, A.J. Flood boundary delineation from synthetic aperture radar imagery using a statistical active contour model. Int. J. Remote Sens. 2001, 22, 2489-2507. [CrossRef]

103. Hooshyar, M.; Singh, A.; Wang, D. Hydrologic controls on junction angle of river networks. Water Resour. Res. 2017. [CrossRef]

104. Medeiros, S.; Hagen, S.; Weishampel, J.; Angelo, J. Adjusting lidar-derived digital terrain models in coastal marshes based on estimated aboveground biomass density. Remote Sens. 2015, 7, 3507-3525. [CrossRef] 
105. Hladik, C.; Alber, M. Accuracy assessment and correction of a LIDAR-derived salt marsh digital elevation model. Remote Sens. Environ. 2012, 121, 224-235. [CrossRef]

106. Moeslund, J.E.; Arge, L.; Bøcher, P.K.; Nygaard, B.; Svenning, J.C. Geographically comprehensive assessment of salt-meadow vegetation-elevation relations using LiDAR. Wetlands 2011, 31, 471. [CrossRef]

107. Huang, C.; Peng, Y.; Lang, M.; Yeo, I.-Y.Y.; McCarty, G. Wetland inundation mapping and change monitoring using Landsat and airborne LiDAR data. Remote Sens. Environ. 2014, 141, 231-242. [CrossRef]

108. Hooshyar, M.; Kim, S.; Wang, D.; Medeiros, S.C. Wet channel network extraction by integrating LiDAR intensity and elevation data. Water Resour. Res. 2015, 51, 10029-10046. [CrossRef]

109. Kim, S.; McGaughey, R.J.; Andersen, H.-E.; Schreuder, G. Tree species differentiation using intensity data derived from leaf-on and leaf-off airborne laser scanner data. Remote Sens. Environ. 2009, 113, 1575-1586. [CrossRef]

110. Tahsin, S.; Medeiros, S.C.; Hooshyar, M.; Singh, A. Optical cloud pixel recovery via machine learning. Remote Sens. 2017, 9, 527. [CrossRef]

111. Barducci, A.; Guzzi, D.; Marcoionni, P.; Pippi, I. Aerospace wetland monitoring by hyperspectral imaging sensors: A case study in the coastal zone of San Rossore Natural Park. J. Environ. Manag. 2009, 90, 2278-2286. [CrossRef] [PubMed]

112. Zhang, K. Analysis of non-linear inundation from sea-level rise using LIDAR data: A case study for South Florida. Clim. Chang. 2010, 106, 537-565. [CrossRef]

113. Klemas, V. Remote sensing of emergent and submerged wetlands: An overview. Int. J. Remote Sens. 2013, 34, 6286-6320. [CrossRef]

114. Klemas, V.V.; Dobson, J.E.; Ferguson, R.L.; Haddad, K.D. A coastal land cover classification system for the NOAA Coastwatch Change Analysis Project. J. Coast. Res. 1993, 9, 862-872.

115. Birkett, C. The global remote sensing of lakes, wetlands and rivers for hydrological and climate research. In Proceedings of the IGARSS '95 Quantitative Remote Sensing for Science and Applications, Firenze, Italy, 10-14 July 1995; pp. 1979-1981.

116. Bartsch, A.; Wagner, W.; Scipal, K.; Pathe, C.; Sabel, D.; Wolski, P. Global monitoring of wetlands-the value of ENVISAT ASAR Global mode. J. Environ. Manag. 2009, 90, 2226-2233. [CrossRef] [PubMed]

117. Marechal, C.; Pottier, E.; Hubert-Moy, L.; Rapinel, S. One year wetland survey investigations from quad-pol RADARSAT-2 time-series SAR images. Can. J. Remote Sens. 2012, 38, 240-252. [CrossRef]

118. Irons, J.R. Landsat Science. Available online: https://landsat.gsfc.nasa.gov/landsat-9/landsat-9-spectralbands / (accessed on 2 April 2018).

119. Mandanici, E.; Bitelli, G. Preliminary Comparison of Sentinel-2 and Landsat 8 Imagery for a Combined Use. Remote Sens. 2016, 8, 1014. [CrossRef]

120. Huck, A. Sentinel-3 Data Benefit Users. Available online: https://sentinel.esa.int/web/sentinel/missions/ sentinel-3/news/-/article/sentinel-3-data-benefit-users (accessed on 3 April 2018).

(C) 2018 by the authors. Licensee MDPI, Basel, Switzerland. This article is an open access article distributed under the terms and conditions of the Creative Commons Attribution (CC BY) license (http:/ / creativecommons.org/licenses/by/4.0/). 